\title{
Experimental and Numerical Investigation of the Effects of Different Draft and Wave Frequency Combinations on the Performance of a Fixed OWC Wave Energy Converter
}

\author{
(1) Deniz Öztürk, (1) Mehmet Ozan Şerifoğlu \\ İstanbul Technical University, Faculty of Naval Architecture and Ocean Engineering, Department of Shipbuilding and Ocean \\ Engineering, İstanbul, Turkey
}

\begin{abstract}
The oscillating water column (OWC) device is a versatile type of wave energy converter, which is one of the promising and popular systems in the use of sustainable supplies of energy. The present research aims to investigate the hydrodynamic performance of a cylindrical OWC device within several approaches, thereby observing the effects of varying wave heights and vertical positions on the flow inside the device. A series of experiments and numerical analyses were performed on a fixed OWC device with an open orifice for three different drafts $(0.25,0.40$, and $0.55 \mathrm{~m})$ and regular waves with frequencies ranging between $0.4 \mathrm{~Hz}$ and $1.2 \mathrm{~Hz}$. Present results were compared with the results derived from the analytical calculations. The trends observed in the analytical solutions in a response amplitude operator for the heave motion of the internal water free surface with the wave frequency variation for all drafts were consistent with the numerical and experimental results. The findings reveal that the maximum water displacement inside the OWC increases as the draft increases, and the optimal frequency at which this value appears decreases.
\end{abstract}

Keywords

Oscillating water column, Regular waves, Renewable energy, Computational fluid dynamics, Volume of fluid

\section{Introduction}

The growing demand for energy consumption in the world requires a rapid increase in energy production. Production through non-renewable sources is not sustainable for future energy needs and can create harmful effects for the environment. As a result, the development of renewable energy sources becomes important to support and replace non-renewable sources. Renewable energy sources can be mainly categorized as hydropower, solar photovoltaic, wind energy, bioenergy, geothermal energy, and ocean energy [1]. Ocean energy consists of ocean current energy, tidal energy, and wave energy. The European Renewable Energy Council stated that the ocean is a very high potential energy source that can meet a significant part of the electricity supply of several European countries [2]. However, energy production using ocean energy stays behind other renewable energy sources. Renewable electricity is $27.3 \%$ of the estimated renewable energy share of the global electricity production in 2020, and the ocean energy constitutes the smallest portion with a share of $0.4 \%$ [3]. In addition, geothermal power and concentrated solar power are also included in this percentage. The reason why these systems are uncommon is may be due to the inefficiency of ocean energy production methods or the high risks associated with the operation of energy generators. Whatever the reasons are, ocean energy generation should be investigated further and improved to reach its actual potential.

There are numerous types of wave energy generators such as point absorbers, attenuators, overtopping devices, and oscillating water columns [4]. Most of these systems function by transferring the motion of water to a hydraulic or pneumatic power take-off (PTO) system and converting the associated energy to electricity. The oscillating water

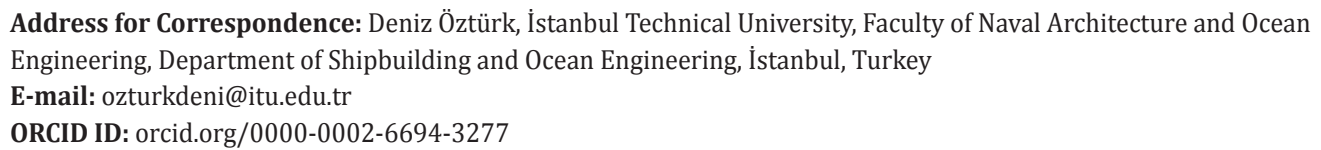

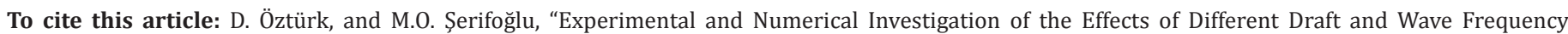
Combinations on the Performance of a Fixed OWC Wave Energy Converter." Journal of ETA Maritime Science, vol. 9(4), pp. $266-273,2021$.

C Copyright 2021 by the Journal of ETA Maritime Science published by UCTEA Chamber of Marine Engineers 
column (OWC) is a type of wave energy generator that works by the exchange of air in and out of a turbine. Air is moved through the turbine by the change of the water level (with the waves) inside the OWC. The rotation of the turbine is then converted to electrical energy. Bidirectional turbines are used to establish continuous turbine rotation in the same direction during reciprocation. The OWC device has three main steps of conversion [5]: wave to pneumatic energy (water to air), pneumatic to mechanical energy (air to turbine), and mechanical to electrical energy (turbine to electricity). OWC generators can be established onshore as a fixed platform or on breakwaters, or they can be built offshore as floating types with various kinds of moorings.

OWC wave energy converters are investigated in numerous studies with various engineering methods, examining the effects of different cross sections, dimensions, turbine types, and fields of operation. McCormick [6] presented a theoretical model for the wave height-power relationship in floating OWC devices. In the study, the compressibility of air is neglected to simplify the physical phenomenon, so the effects caused by viscosity were not observed in the results. However, the approach is very useful in giving a preliminary idea about the power produced by the buoy. Afterward, the author modified the theory in $[7,8]$ in the light of the experimental studies. Martins-Rivas and Mei [9] studied the effects of the incident wave angle for a circular OWC fixed at the end of a breakwater and found that the angle of incidence is not important in the energy production for the studied OWC geometry. In a parallel study, Martins-Rivas and Mei [10] also inspected the impacts of the coastline on the absorption of the wave power by analyzing an OWC fixed on a vertical cliff. They computed and compared coefficients of radiation damping, chamber pressure, and apparent mass to OWCs positioned offshore or on a breakwater. The authors concluded that the system response of an OWC fixed at the coastline depends more on the incident wave angle compared to that of offshore or breakwater cases. Gomes et al. [11] conducted a study to optimize the dimensions of a fixed OWC in a two degrees-of-freedom system using the linear wave theory. In the study, the authors stated that the dimensions of submerged and air-contained parts of the structure affect the annual power extraction. It was further revealed that the floating structure should be optimized for efficient conversion. Crema et al. [12] conducted experiments on a rectangular cross-section OWC (Figure 1a) using varied chamber sizes, drafts, and turbine damping before equipping a large floating structure with several OWCs. As it is hard to scale the turbine properties for the model experiments, turbines are represented by different sizes of orifices when the turbine damping effects are to be considered. A scaled model of the OWC was tested by Correia da Fonseca et al. [13] to determine the chamber air pressure, OWC motion in waves, and mooring line forces (Figure 1b). Henriques et al. [14] employed a systematic methodology including parameters of the geometry and the PTO system to design a wave energy converter. Elhanafi and Kim [15] experimentally tested a rectangularshaped OWC with an orifice using regular waves with changing periods and heights and validated results by three-dimensional incompressible computational fluid dynamics (CFD) techniques. Although the effect of a single orifice was frequently studied in the literature, Elhanafi et al. [16] examined how the energy conversion would be affected in the case of two orifices. As a result of the study in which different orifice diameters were also examined numerically, the energy conversion increased significantly when multiple orifices were used. The scale effect on the air-water interaction in the OWC was investigated by Viviano et al. [17] by comparing small-scale models with two different chamber heights to a previously tested large-scale model. The authors found that the similarity of the wave height inside the OWC is greater between the large-scale model and the high-chamber small-scale model. Çelik and Altunkaynak [18] performed a series of experiments with varying chamber openings and turbineinduced damping of a rectangular OWC. Optimum data were presented by establishing a relation between the incoming wave characteristics and the orifice opening. Another fixed and rectangular cross-section OWC was investigated experimentally by Zabihi et al. [19], considering the sloshing effect in addition to the generally investigated parameters. Effects of sloped and perpendicular walls in an onshore OWC (Figure 1c) were numerically studied by Gaspar et al. [20]. Jalón and Brennan [21] inspected hydrodynamic performance and structural endurance of a bottom fixed OWC, which can be adapted to consecutive sea states. Their results revealed that in addition to providing ideal hydrodynamic efficiency, an adaptive system allows less cumulative fatigue damage. Moreover, the rotation speed of the turbine and the draft of the OWC are the essential variables regarding hydrodynamic efficiency. The physical modeling of an OWC in experiments leads to constraints that allow the effect of air compression to be neglected. Thus, López et al. [22] focused on the air volume scaling in the OWC. Findings of compressible and incompressible setups showed that air compressibility is an important factor in OWC efficiency. Since the OWC can be designed in different cross sections as well as integrated with floating breakwater, Howe et al. [23] experimentally examined the effect of incoming wave characteristics in different device configurations. Ning et al. [24] experimentally investigated the efficiency of a dual-chamber OWC by considering the effects of wave steepness, opening ratio, and internal and 

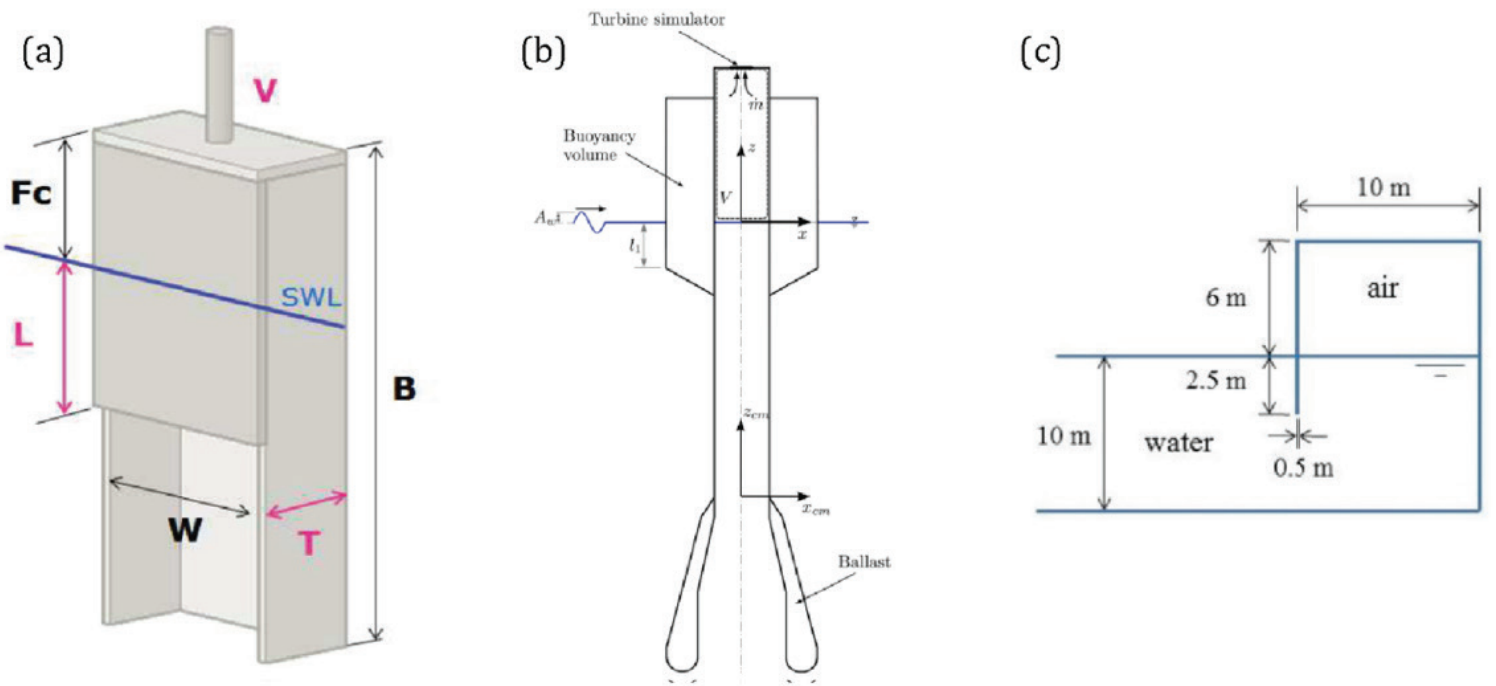

Figure 1. Sketches for different types of OWC devices in the literature: (a) rectangular cross-section OWC [12], (b) spar-buoy wave energy converter [13], (c) onshore type OWC [20]

OWC: Oscillating water column

external drafts. The hydrodynamic performance of the OWC was recently investigated by considering the novel designs with dual chambers [25-28].

OWC systems share a wide range of basic working principles with other wave energy generators and create a basis for understanding those principles. Motivations of this study can be listed as (1) comprehending the working principles of basic OWC systems and (2) understanding the effects of various parameters, i.e., draft and wave frequency, on the OWC internal motion. Therefore, the internal motion height in the cylinder representing a fixed OWC system was explored under regular wave conditions for three drafts $(0.25,0.40$, and $0.55 \mathrm{~m})$ and different wave frequencies ranging between $0.4 \mathrm{~Hz}$ and $1.2 \mathrm{~Hz}$.

\section{Experimental Investigation}

Experiments were performed in the Ata Nutku Ship Model Testing Laboratory of İstanbul Technical University (ITU). The OWC model was mounted on a towing carriage with a support rod to prevent the cylinder motion as can be seen in Figure 2. Mounting the cylinder to a vertical position adjuster facilitated draft modification processes without disassembling the cylinder from the towing tank. A comparison of the water level inside the cylinder to the wave height is directly relative to the power output of the OWCs. Therefore, the change in the water level inside the cylinder was measured. Two of the SICK DT35 laser distance sensors were located at the top of the cylinder to measure the change of the water level. Laser sensors were
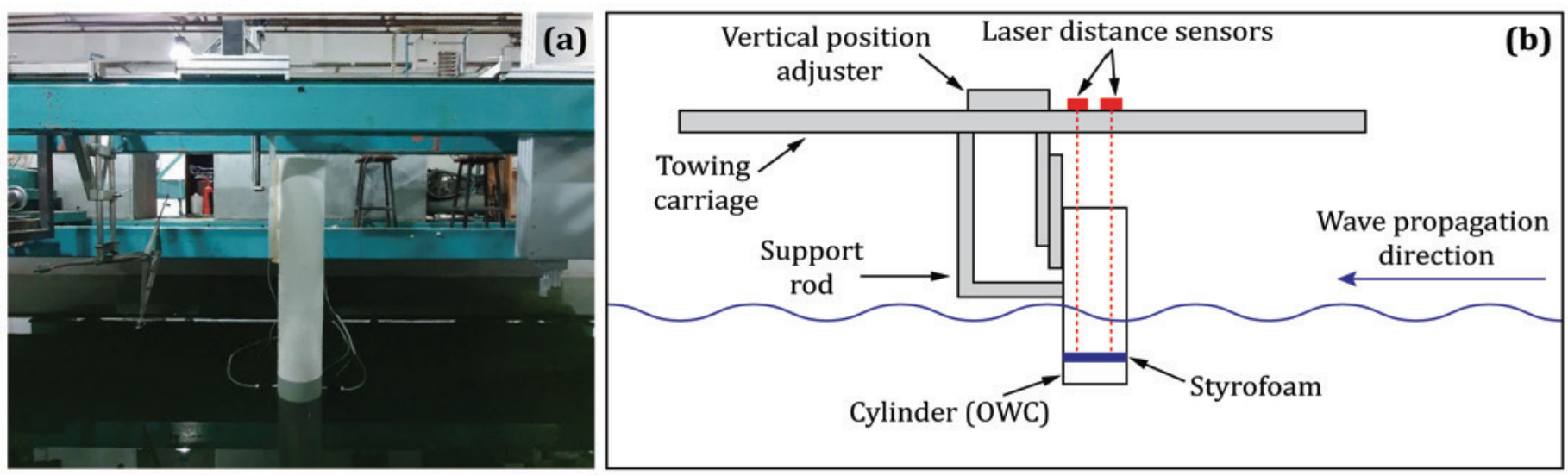

Figure 2. (a) Experimental setup of the OWC, (b) schematic diagram with laser distance sensor positions oWC: Oscillating water column 
calibrated and tested for their accuracy beforehand. As a target, a reflective and fully buoyant styrofoam that moves depending on water level changes was located inside the cylinder. A commercial data logger and its respective data acquisition software were used to collect data from laser distance sensors. An appropriate low pass filter built into the data acquisition system was employed for each case to filter out the noise in the gathered data. Additionally, a sampling rate higher than the Nyquist rate was set for the sensors to avoid aliasing.

Two reasons for choosing a fixed OWC structure include (1) the robustness and safety of fixed devices under all sea conditions (with the disadvantage of having a low efficiency) and (2) being free of variables, a floating OWC device would introduce through different kinds of mooring options. With these, obtaining a clearer view of the effects of draft and wave frequency variation was possible.

The outer diameter of the OWC model is $0.25 \mathrm{~m}$. The model has a wall thickness of $4.9 \mathrm{~mm}$ and an inner diameter of 0.24 $\mathrm{m}$. The total length of the model was set to $1.50 \mathrm{~m}$ to adjust the freeboard of the model with a changing draft. The draft effect on the water level inside the OWC was carried out by changing the draft. Tested drafts $(d)$ are $0.25 \mathrm{~m}, 0.40 \mathrm{~m}$, and $0.55 \mathrm{~m}$. The selected material of the OWC model is polyvinyl chloride due to the availability of desired dimensions and formability capabilities of the material. Distance markers were placed on the OWC surface to visualize the wave height and practical draft change.

The effect of the wave frequency on the water level inside the OWC was also tested with changing wave frequencies of $0.4,0.5,0.6,0.8,0.9,1.0$, and $1.2 \mathrm{~Hz}$ at each draft. Regular waves were generated with a constant height of $0.12 \mathrm{~m}$ in the towing tank. Note that the waves require damping before the next run. Otherwise, a regular wave formation may be disturbed because of the overlapping waves and decrease the accuracy of the measurement.

\section{Numerical Modeling}

\subsection{Physics Modeling}

The standard $k-\varepsilon$ turbulence model was preferred among a variety of turbulence models to solve the closure problem. Spatial discretization of convective terms in Reynolds-averaged Navier-Stokes equations was performed with the $2^{\text {nd }}$ order solution scheme. The free surface forming the interface between water and air was determined using the volume-of-fluid method (VOF) in numerical analyses. The method works by calculating the part of the light (air) and heavy (water) fluid in each cell in multiphase cases. Accurately established free-surface simulations also show that water and air particles are separated by a sharp interface. Therefore, the VOF method was applied by the high-resolution interface-capturing scheme to get a numerical diffusion or dispersion error at a level that does not affect the solution. Second-order temporal discretization was performed in all computations because a false diffusion effect could occur at the water-air interface and the damping effect on the wave height would be dominant if the first-order discretization was preferred. In this study, hydrodynamic analysis of a fixed-type OWC was carried out by CFD methods with the commercial CFD code Siemens PLM STAR-CCM+.

\subsection{Computational Domain and Boundary Conditions}

To solve the physical problem numerically, a computational domain needs to be correctly selected. Boundaries of the computational domain should be sufficiently far from the region where solution accuracy is critical, and the computational cost should also be considered. The fact that the distance of the inlet, outlet, and lateral surfaces to any geometry is too small may adversely affect the numerical results. Generally, the flow with a high amount of irregularity near the outlet boundary and the outlet boundary with a uniform pressure definition lead to this problem. It can be said that the outlet boundary is very close to the geometry that causes irregular flow. To avoid this problem, the outlet should be positioned at a distance where the flow takes a regular form before it reaches the boundary. For a cylinder diameter $\mathrm{D}$, dimensions of the computational domain are determined from the center of the cylinder as can be seen in Figure 3. The computational domains were created for each wave condition. It should be also noted that analyses were carried out with a half model to investigate the oscillating flow inside the OWC structure.

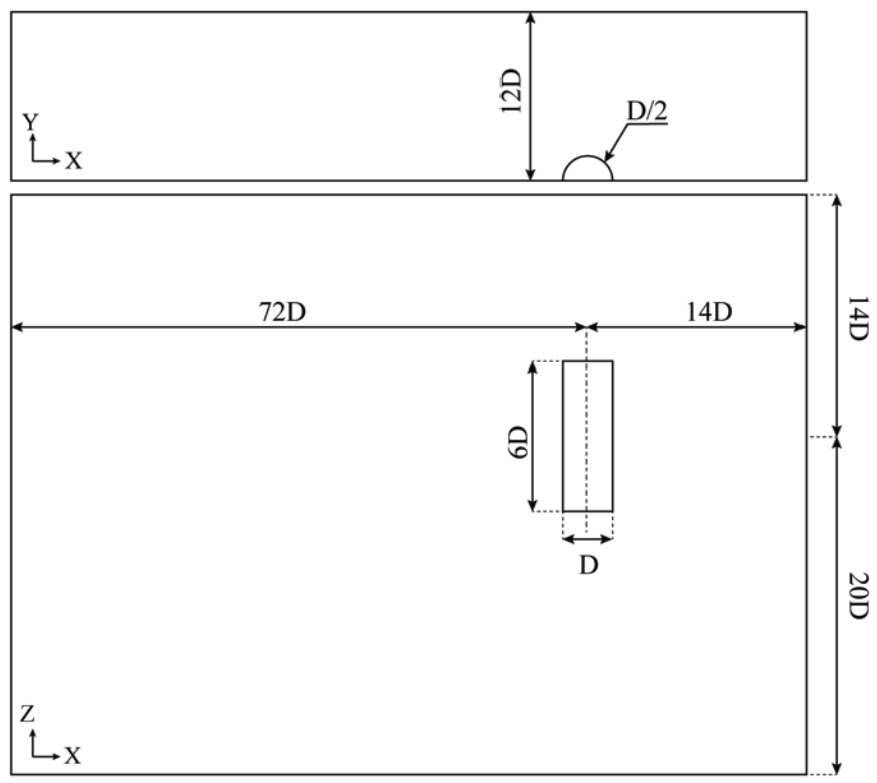

Figure 3. Dimensions of the numerical wave tank 
Figure 4 illustrates the boundary conditions for the numerical setup for a fixed-type OWC. The positive $x$-direction, which is the direction of the generation of the regular wave during the analysis, and the top boundary were modeled as velocity inlets. The symmetry condition is applied to the symmetry plane and the side of the domain to avoid reflection. The plane behind the cylinder was set as the pressure outlet boundary condition to prevent backflow. The boundary condition of the cylinder and the bottom of the domain were selected as the no-slip wall.

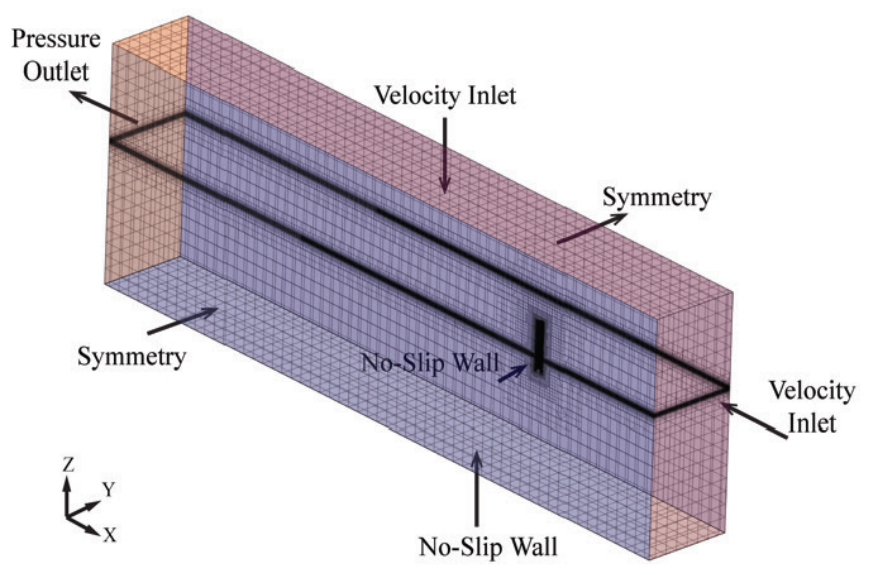

Figure 4. Boundary conditions of numerical wave tank

\subsection{Mesh Generation}

The grid structure should be generated according to certain rules to avoid distortion of the free surface layer as the wave travels [29]. It is known that the wave height is constant and if the wave steepness ratio $(H / \lambda$, where $\mathrm{H}$ is the wave height and $\lambda$ is the wavelength) is greater than $1 / 7$ (critical wave steepness ratio), then the wave is considered to be very steep. However, under present conditions, the preferred waveforms are quite far from becoming a steep wave. Thus, refinement in the direction of the wave height $(+z)$ was kept constant and refinement in the $x$-axis was changed by changing the wavelength.

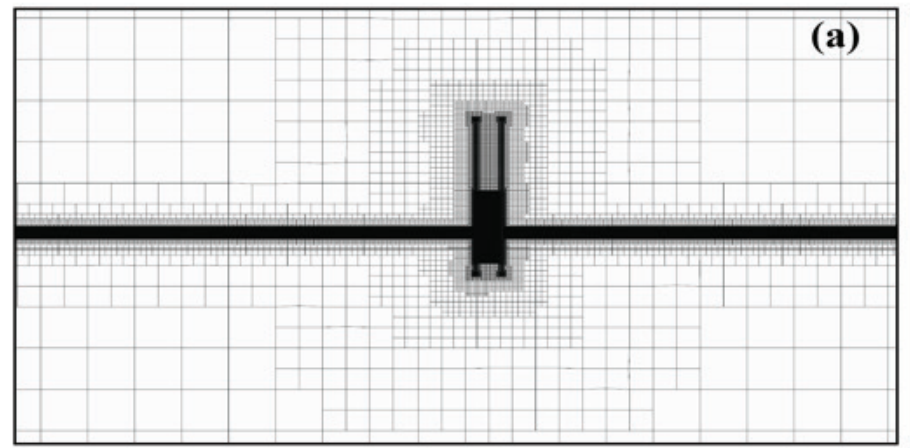

Various studies in the literature that can be used as a guide for creating a successful phase separation for the free surface problem. CD-Adapco recommends 80-100 and 20 cells per wavelength and per wave amplitude respectively [30], while the International Towing Tank Conference guideline recommends 10 to 40 cells [31]. 20 cells for each wave amplitude in the $z$-axis and 80 cells for the $x$-axis for each wavelength were preferred in the mesh generation. Figure 5 illustrates the mesh generation and volume fraction of the free surface for the case of $d=0.40$ m and $f_{w}=1.0 \mathrm{~Hz}$, where $d$ is the draft and $f_{w}$ is the wave frequency. As a result, between 2 million and 3.5 million cells were used in total. A grid independence study was not performed in the study. Mesh combinations proposed in the literature proved to provide convincing outcomes [6]. The main solution parameters in Table 1 were used in numerical computations.

Table 1. Solution parameters

\begin{tabular}{|c|c|}
\hline Parameter & Value \\
\hline Grid number & $2.5-3 \mathrm{M}$ \\
\hline Maximum inner iteration & 5 \\
\hline Time step & $0.004-0.013 \mathrm{~s}$ \\
\hline Solution time & $25 \mathrm{~s}$ \\
\hline Elapsed time & $\sim 8.1 \mathrm{~h}$ \\
\hline Convergence criteria & $10 \mathrm{E}-3$ \\
\hline
\end{tabular}

\subsection{Wave Modeling}

The first-order VOF wave used in numerical simulations was modeled to have a regular periodic sinusoidal profile. The elevation of the free surface is defined as (formula 1 is below):

$$
\eta(x, t)=A \cos (k x-\omega t)
$$

where $\mathrm{A}$ is the wave amplitude, $\omega$ is the wave frequency, $\mathrm{k}$ is the wave number, $\mathrm{k}=2 \pi / \lambda, t$ is the time, and $\lambda$ is the

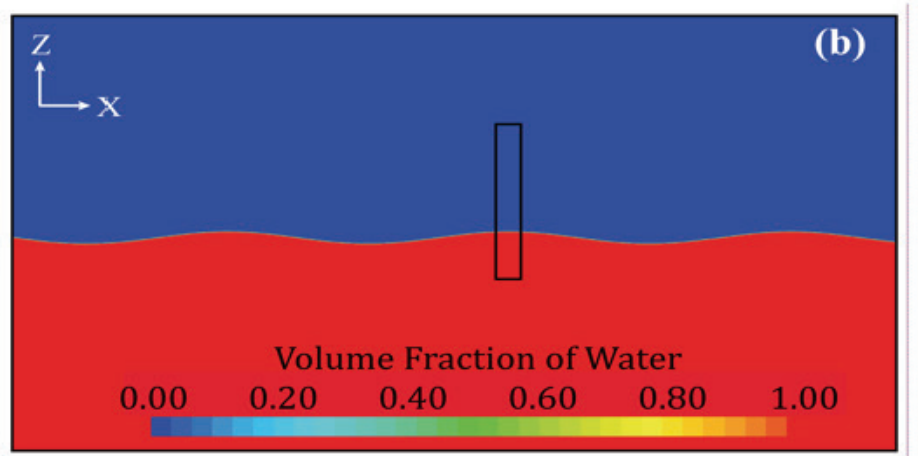

Figure 5. Numerical wave tank $(d=0.40 \mathrm{~m}, \mathrm{fw}=1.0 \mathrm{~Hz})$ : (a) mesh generation of the xz plane, (b) volume fraction of water 
wavelength. The dispersion relation, between the wave period, $T_{w^{\prime}}$ and the wavelength, $\lambda$, for first-order waves in finite water is (formula 2 is below):

$$
\omega^{2}=g k \tanh k h
$$

The deepwater wave assumption was considered to calculate the wave frequencies. According to the deepwater assumption, the water depth should be greater than half of the wavelength. In the study conducted at a constant wave height, regular wave frequencies ranged between $0.4 \mathrm{~Hz}$ and $1.2 \mathrm{~Hz}$. Table 2 gives the wave parameters preferred in numerical calculations. The time step was also determined according to the wave periods, $\mathrm{T}_{\mathrm{w}}$, and the refinement number for cells per wavelength, $\mathrm{n}$ (formula 3 is below):

$\Delta t=\frac{T_{w}}{n \times 2.4}$

Wave reflection directly affects the results in both experimental and numerical wave tanks. It is important that forcing or damping conditions at the boundaries are appropriately applied in VOF modeling. By this means, wave oscillations and reflections can be reduced around the boundaries. While various damping/forcing methods can be applied on a numerical wave tank [32] the effects of these methods were not extensively studied in the present study. Instead, the damping length, $x_{d^{\prime}}$ was selected to be equal to the wavelength from the outlet boundary to the positive $x$-direction. It can be noted that only small reflections are visible at $x_{d}=\lambda$ where the damping length is equal to the wavelength.

\section{Results}

Figure 6 illustrates the final results from the experiments, numerical simulations, and analytical solutions in terms of wave frequency-response amplitude operator (RAO) relations. The change in the water level inside the OWC is calculated as the mean of the peak-to-peak value of the oscillations inside the cylinder for all methods. Numerical and experimental outcomes for the water level inside
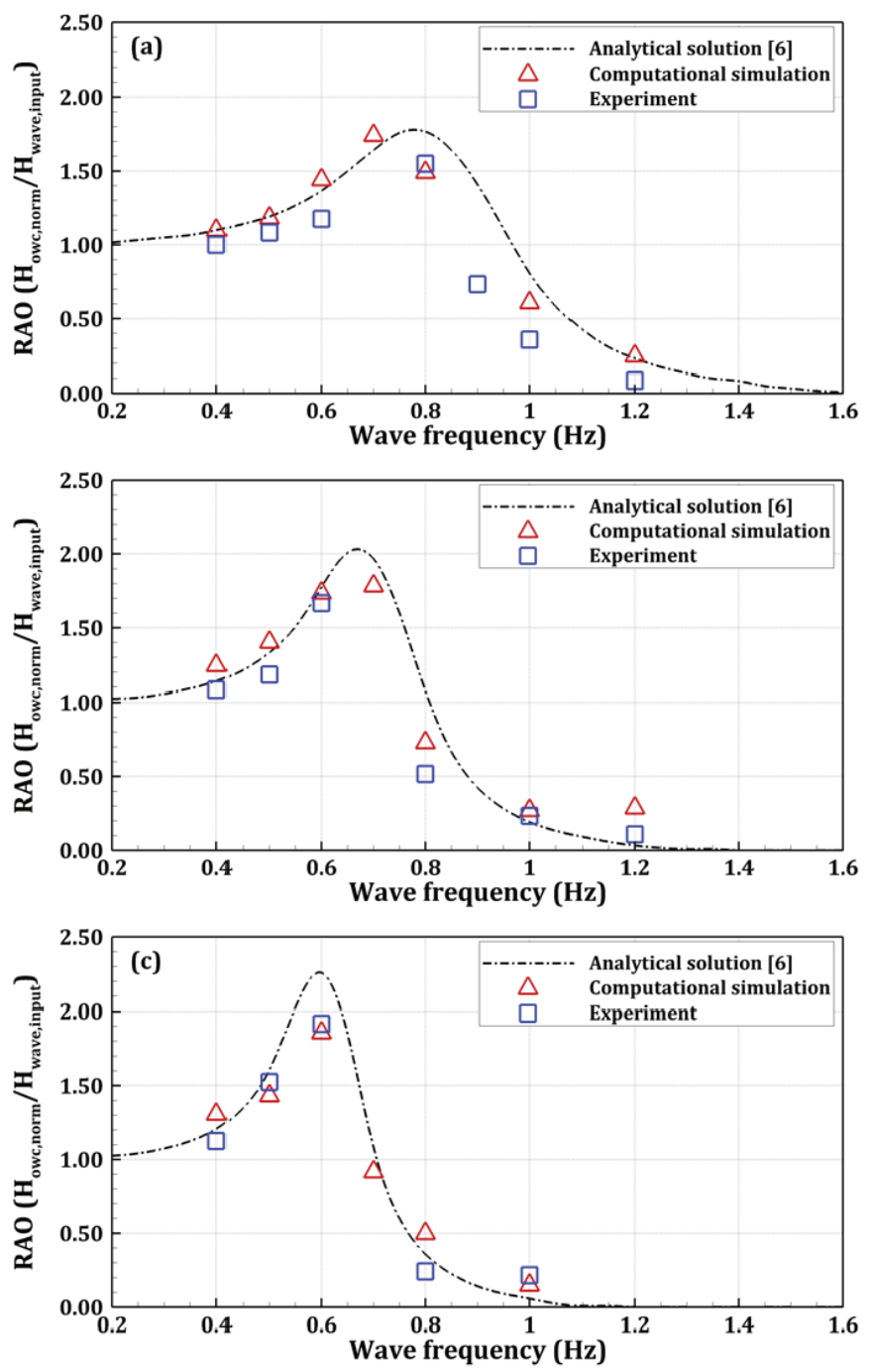

Figure 6. Non-dimensionalized internal motion comparison for (a) $d=0.25 \mathrm{~m}$, (b) $d=0.40 \mathrm{~m}$, and (c) $d=0.55 \mathrm{~m}$

RAO: Response amplitude operator

Table 2. Regular wave parameters

\begin{tabular}{|c|c|c|c|c|c|}
\hline Wave height & Wave length & Wave period & Wave frequency & Wave steepness & Damping length \\
\hline$H_{\text {wave,input }}$ & $\lambda$ & $T_{w}$ & $f_{w}$ & $\varepsilon$ & $x_{d}$ \\
\hline m & m & $\mathbf{s}$ & $\mathrm{Hz}$ & - & $\mathbf{m}$ \\
\hline \multirow{7}{*}{0.12} & 9.50 & 2.50 & 0.40 & 0.01 & 9.50 \\
\hline & 6.24 & 2.00 & 0.50 & 0.02 & 6.24 \\
\hline & 4.34 & 1.67 & 0.60 & 0.03 & 4.34 \\
\hline & 2.44 & 1.25 & 0.80 & 0.05 & 2.44 \\
\hline & 1.27 & 1.11 & 0.90 & 0.09 & 1.27 \\
\hline & 1.56 & 1.00 & 1.00 & 0.08 & 1.56 \\
\hline & 1.08 & 0.83 & 1.20 & 0.11 & 1.08 \\
\hline
\end{tabular}


the OWC $\left(H_{\text {owc }}\right)$ were compared to each other in a nondimensionalized form. The obtained water level inside the OWC is normalized as follows (formula 4 is below):

$$
H_{\text {owc,norm }}=\frac{H_{\text {owc }}}{H_{\text {wave,out }}} \times H_{\text {wave,input }}
$$

The RAO of the water level inside the OWC is calculated by the following equation (formula 5 is below):

$R A O=\frac{H_{\text {owc,norm }}}{H_{\text {wave, input }}}$

Analytical results were derived using concepts and equations presented in the study of McCormick [6]. To attain an understanding of the overall performance of the more complicated OWC, one must first understand the nature of the free-surface motions of a simple orifice system. To fully analyze the free-surface motion within the OWC, the compressibility of the air and the viscosity of the flow must be taken into account. However, the compared analytical method did not take into account some of these physical conditions to simplify the problem. It is assumed that the air is incompressible and a loss term is used to represent the viscosity. Moreover, due to experimental limitations, the motion of the OWC and the mooring systems were not included in the experimental setup. These constraints align with the approach of the analytical solution.

The trends observed in the analytical solutions for all drafts are consistent with numerical and experimental results. The results can be detailed as follows.

- Due to viscous effects, the results obtained from the experimental and numerical solutions are observed to be lower around the peak frequency than the analytical results. A successful match was achieved at low and high frequencies.

- The maximum water level change is observed to increase as the draft increases and the frequency at which this value is observed (natural frequency) decreases.

- Maximum RAO values obtained from the experiments and numerical solutions were found to be compatible. The peak value was around $0.8 \mathrm{~Hz}, 0.7 \mathrm{~Hz}$, and $0.6 \mathrm{~Hz}$ for $d=0.25 \mathrm{~m}$, $d=0.40 \mathrm{~m}$, and $d=0.55 \mathrm{~m}$, respectively.

- The RAO value used in the results can be expressed as the ratio of the amplitude of the water motion in the OWC to the incoming wave amplitude. For RAO values greater than 1 , the change in the water height in the OWC is greater than the incoming wave height.

\section{Conclusion}

In this study, the internal motion height in the cylinder representing a fixed OWC system was investigated to understand the effects of important parameters such as the draft and wave frequency on the system. Therefore, systematic experiments were carried out using the towing tank and wave-making device in the Ata Nutku Ship Model Testing Laboratory of ITU under three different drafts and different wave frequencies in regular waves. Numerical simulations and analytical calculations were also conducted to compare and support the experimental results.

The findings reveal that increasing the draft of an OWC also increases the general performance of the system. Conversely, variation in the OWC draft creates a change in the optimal wave frequency of the system and thus may decrease the efficiency of the converter for a specific operation site.

Even though a correlation between the draft value and the performance of the OWC was achieved, it may not be possible to estimate how this trend would continue due to a limited number of drafts tested in the experiments. There can be a point in the draft values for which the increase in the RAO plateaus or drops back. Therefore, further studies can be performed with a wider draft range to determine the behavior.

This study should also be extended to incorporate the orifice diameter and the turbine effect, as these will also have a notable effect on energy conversion. With the present cylinder and suitable mooring methods used to represent its oscillation, a future study on the changes in the energy output could be made. Also, a precise pressure sensor will increase the accuracy of the data, and comparison with the laser distance sensor will increase the precision.

\section{Authorship Contributions}

Concept design: D. Öztürk, M.O. Şerifoğlu, Data Collection or Processing: D. Öztürk, M.O. Şerifoğlu, Analysis or Interpretation: D. Öztürk, M.O. Șerifoğlu, Literature Review: D. Öztürk, M.O. Şerifoğlu, Writing, Reviewing and Editing: D. Öztürk, M.O. Şerifoğlu.

Funding: The author(s) received no financial support for the research, authorship, and/or publication of this article.

\section{References}

[1] O. Ellabban, H. Abu-Rub, and F. Blaabjerg, "Renewable energy resources: Current status, future prospects and their enabling technology," Renewable Sustainable Energy Review, vol. 39, pp. 748-764, 2014.

[2] European Renewable Energy Council (EREC), Renewable energy in Europe: Markets, trends and technologies, $2^{\text {nd }} \mathrm{ed}$. Washington, 2010.

[3] REN21, “Renewables 2020 Global Status Report," Paris, 2020. 
[4] S. P. Neill and M. R. Hashemi, Fundamentals of Ocean Renewable Energy. Elsevier Ltd., 2018.

[5] B. Kooverji, "Pneumatic Power Measurement of an Oscillating Water Column Converter," Stellenbosch University, 2014.

[6] M. E. McCormick, "Analysis of a wave energy conversion buoy," Journal of Hydronautics, vol. 8, pp. 77-82, 1974.

[7] M. E. McCormick, "Analysis of a stationary pneumatic waveenergy converter," Journal of Engineering for Industry, vol. 97, pp. 1015-1019, 1975.

[8] M. E. McCormick, "A modified linear analysis of a wave-energy conversion buoy," Ocean Engineering, vol. 3, pp. 133-144, May 1976.

[9] H. Martins-Rivas and C. C. Mei, "Wave power extraction from an oscillating water column at the tip of a breakwater," Journal of Fluid Mechanics, vol. 626, pp. 395-414, May 2009.

[10] H. Martins-Rivas and C. C. Mei, "Wave power extraction from an oscillating water column along a straight coast," Ocean Engineering, vol. 36, pp. 426-433, May 2009.

[11] R. P. F. Gomes, J. C. C. Henriques, L. M. C. Gato, and A. F. O. Falcão, "Hydrodynamic optimization of an axisymmetric floating oscillating water column for wave energy conversion," Renewable Energy, vol. 44, pp. 328-339, Aug 2012.

[12] I. Crema, I. Simonetti, L. Cappietti, and H. Oumeraci, "Laboratory Experiments on Oscillating Water Column Wave Energy Converters Integrated in a Very Large Floating Structure.," Proc. $11^{\text {th }}$ Eur. Wave Tidal Energy Conf. 6-11 ${ }^{\text {th }}$ Sept 2015, Nantes, Fr., vol. 97, pp. 194-200, 2015.

[13] F. X. Correia da Fonseca, R. P. F. Gomes, J. C. C. Henriques, L. M. C. Gato, and A. F. O. Falcão, "Model testing of an oscillating water column spar-buoy wave energy converter isolated and in array: Motions and mooring forces," Energy, vol. 112, pp. 1207-1218, Oct 2016.

[14] J. C. C. Henriques, J. C. C. Portillo, L. M. C. Gato, R. P. F. Gomes, D. N. Ferreira, and A. F. O. Falcão, "Design of oscillating-water-column wave energy converters with an application to self-powered sensor buoys," Energy, vol. 112, pp. 852-867, Oct 2016.

[15] A. Elhanafi and C. J. Kim, "Experimental and numerical investigation on wave height and power take-off damping effects on the hydrodynamic performance of an offshore-stationary OWC wave energy converter," Renewable Energy, vol. 125, pp. 518-528, Sep 2018.

[16] A. Elhanafi, G. Macfarlane, and D. Ning, "Hydrodynamic performance of single-chamber and dual-chamber offshorestationary Oscillating Water Column devices using CFD," Applied Energy, vol. 228, pp. 82-96, Jun 2018.

[17] A. Viviano, S. Naty, and E. Foti, "Scale effects in physical modelling of a generalized OWC," Ocean Engineering, vol. 162, pp. 248-258, April 2018.

[18] A. Çelik and A. Altunkaynak, "Experimental investigations on the performance of a fixed-oscillating water column type wave energy converter," Energy, vol. 188, Dec 2019.
[19] M. Zabihi, S. Mazaheri, and M. M. Namin, "Experimental hydrodynamic investigation of a fixed offshore Oscillating Water Column device," Applied Ocean Research, vol. 85, pp. 20-33, Jun 2019.

[20] L. A. Gaspar, P. R. F. Teixeira, and E. Didier, "Numerical analysis of the performance of two onshore oscillating water column wave energy converters at different chamber wall slopes," Ocean Engineering, vol. 201, pp. 107119, Jun 2020.

[21] M. L. Jalón and F. Brennan, "Hydrodynamic efficiency versus structural longevity of a fixed OWC wave energy converter," Ocean Engineering, vol. 206, Feb 2020.

[22] I. López, R. Carballo, F. Taveira-Pinto, and G. Iglesias, "Sensitivity of OWC performance to air compressibility," Renewable Energy, vol. 145, pp. 1334-1347, Jan 2020.

[23] D. Howe, J. R. Nader, and G. Macfarlane, "Experimental investigation of multiple Oscillating Water Column Wave Energy Converters integrated in a floating breakwater: Energy extraction performance," Applied Ocean Research, vol. 97, pp. 102086, April 2020.

[24] D.-z. Ning, R.-q. Wang, L.-f. Chen, and K. Sun, "Experimental investigation of a land-based dual-chamber OWC wave energy converter," Renewable Sustainable Energy Review, vol. 105, pp. 48-60, May 2019.

[25] K. Rezanejad, J. F. M. Gadelho, S. Xu, and C. Guedes Soares, "Experimental investigation on the hydrodynamic performance of a new type floating Oscillating Water Column device with dual-chambers," Ocean Engineering, vol. 234, pp. 109307, Aug 2021.

[26] J. F. M. Gadelho, K. Rezanejad, S. Xu, M. Hinostroza, and C. Guedes Soares, "Experimental study on the motions of a dual chamber floating oscillating water column device," Renewable Energy, vol. 170, pp. 1257-1274, Jun 2021.

[27] C. Wang, Y. Zhang, and Z. Deng, "Theoretical analysis on hydrodynamic performance for a dual-chamber oscillating water column device with a pitching front lip-wall," Energy, vol. 226, pp. 120326, Jul 2021.

[28] C. Wang and Y. Zhang, "Wave power extraction analysis on a dual-chamber oscillating water column device composed by two separated units: an analytical study," Applied Ocean Research, vol. 111, pp. 102634, Jan 2021.

[29] D. Ozturk, C. Delen, S. Mancini, M. O. Serifoglu, and T. Hizarci, "Fullscale CFD analysis of Double-M craft seakeeping performance in regular head waves," Journal of Marine Science and Engineering, vol. 9, pp. 504, May 2021.

[30] CD-Adapco, "STAR-CCM+ User Guide Version 13.02." CD-Adapco: New York, NY, USA, 2018.

[31] ITTC, "Practical Guidelines for Ship CFD Applications - 7.5-0302-03," in 27th International Towing Tank Conference, 2014.

[32] A. M. Miquel, A. Kamath, M. A. Chella, R. Archetti, and H. Bihs, "Analysis of different methods for wave generation and absorption in a CFD-based numerical wave tank," Journal of Marine Science and Engineering, vol. 6, pp. 1-21, Jun 2018. 